\title{
túnel alemania federal bajo el elba
}

$575-10$

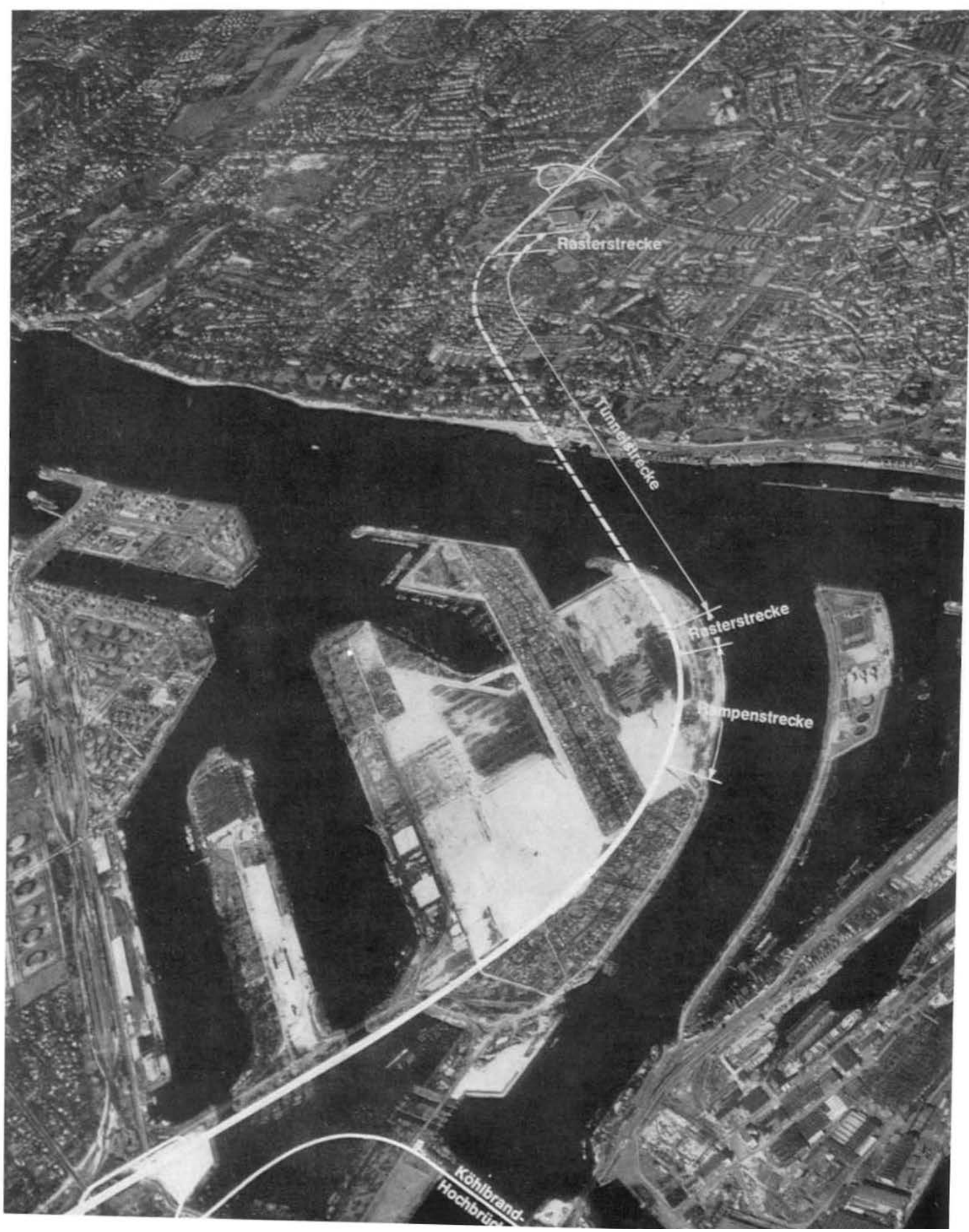




\section{Längsschnitt des Elbtunnels (zchnfach überhöht)}

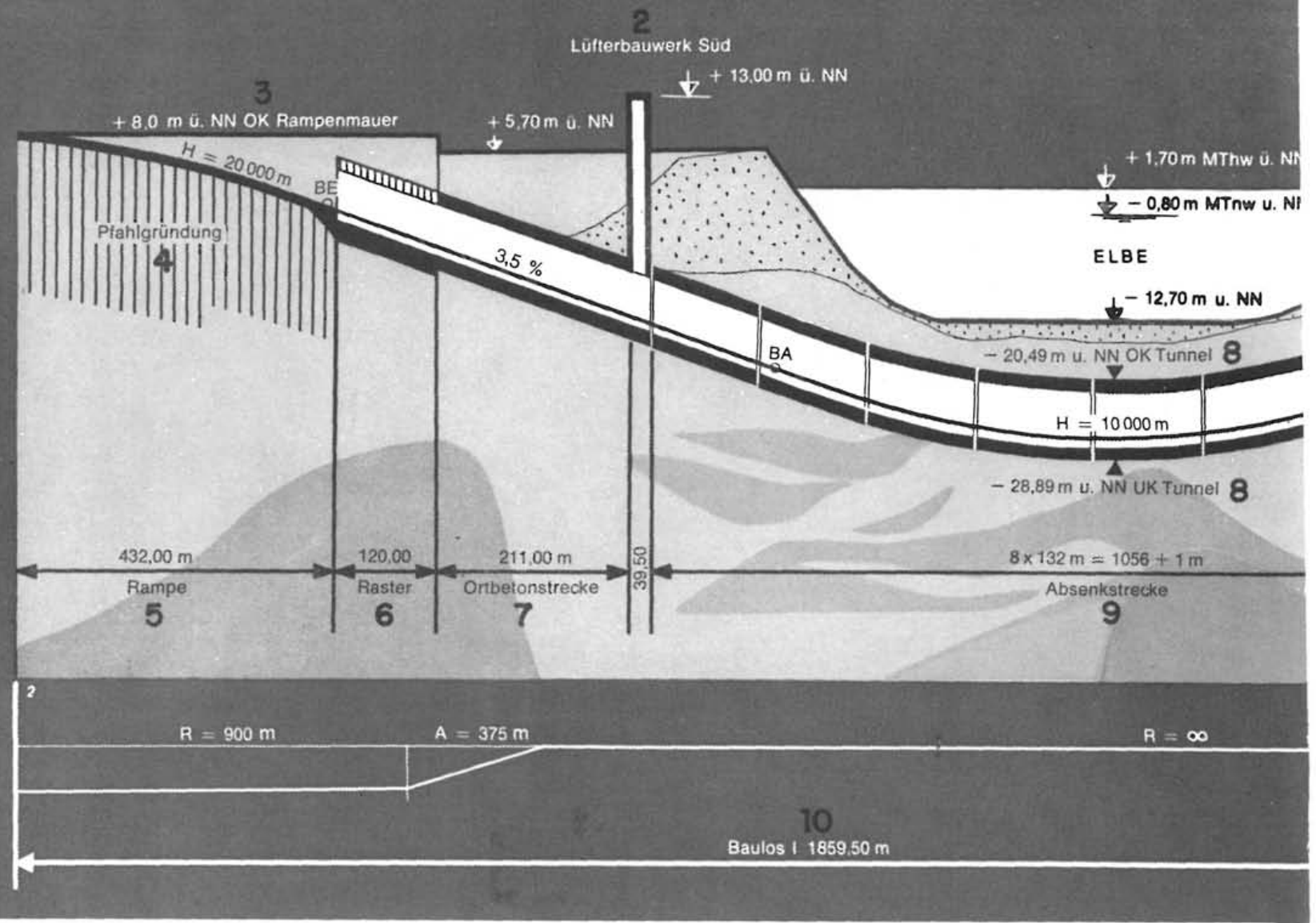

\section{sinopsis}

Esta importante obra, construida para solucionar el problema del tráfico entre las zo tiene una longitud total de $3.325 \mathrm{~m}$. En la mayor parte de su recorrido se utiliza un sistema de aireación especial, abastecido por tres estaciones de ventilación.

El túnel está constituido por tres tubos de circulación independientes, con dos carriles cada uno. Los tubos laterales se utilizan que el central permite la circulación en ambas direcciones.

En el tramo bajo el cauce del río los tres tubos, junto con sus canales de ventilación, se reunen en una pieza única de sección halla formado por o minima. Este tramo se ron construidos en un dique seco de las proximidades para, posteriormente, hundirlos $y$ colocarios en el fondo del rio, en una zanja previamente excavada y dragada. E tecnoló icos muy avanzados de sellod todas las juntas de unión, cubriendo de nue. vo la zanja con los materiales de la exca. vación.

EI tramo bajo el declive más pronunciado del cauce se excavo por el procedimiento finales a tan poca profundidad que permitio el trabajo a cielo abierto.

La estación de ventilación situada al norte, que es una construcción de hormigón armarre con coctras dos estaciol, como ocuademás con la central de seguridad y ripu lación de todo el recorrido, y está equipada con las técnicas más modernas.

\section{sección longitudinal}

1. Sección longitudinal del túnel del Elba (multiplicado por 10 verticalmente) - -2 . Ventilación sur. - 3. Muro de contención rampa.-4. Pilotes.-5. Rampa.-6. Entrada.-7. Hormigonado in situ.-8. Túnel.-9. Zona inferior.-10. Tramo $(1.859,50 \mathrm{~m})$. -11. Ventilación centro.-12. Carretera del Elba.-13. Margas.-14. Arena.-15. Arcilla.-16. Realizada con sección escudo.masa -21 . Cimientos -22 . Yeso -23 . Piedra blanda -24 . Tramo III $(325 \mathrm{~m})$

\section{tramo 1}

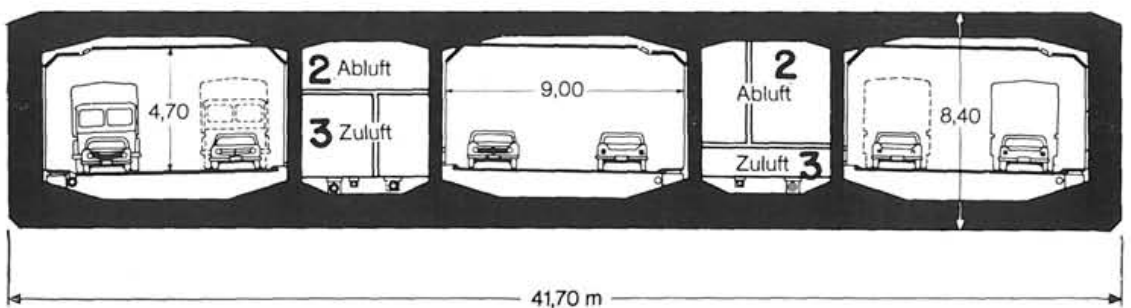




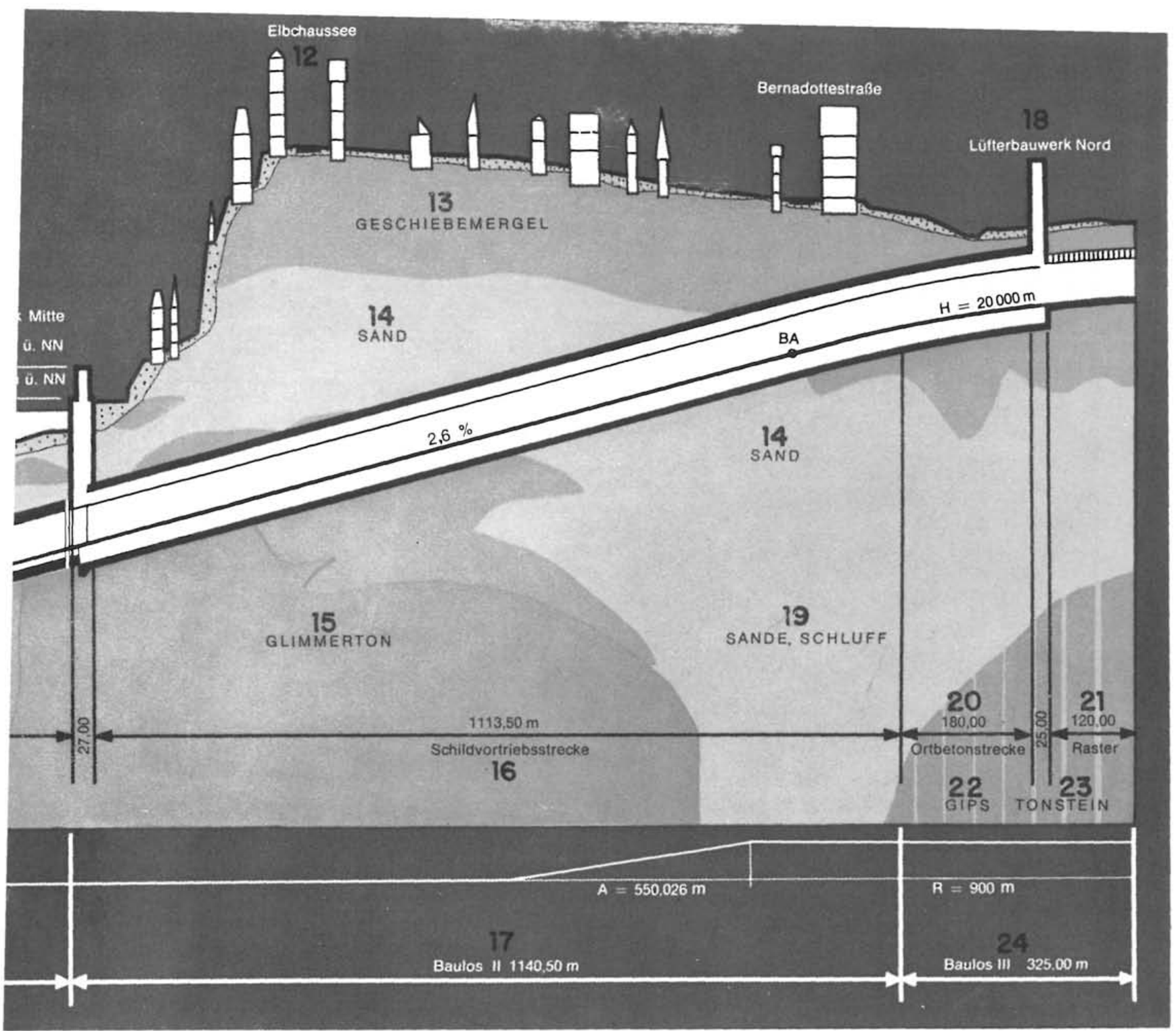

2uerschnitt Baulos II Schildvortriebsstrecke

4
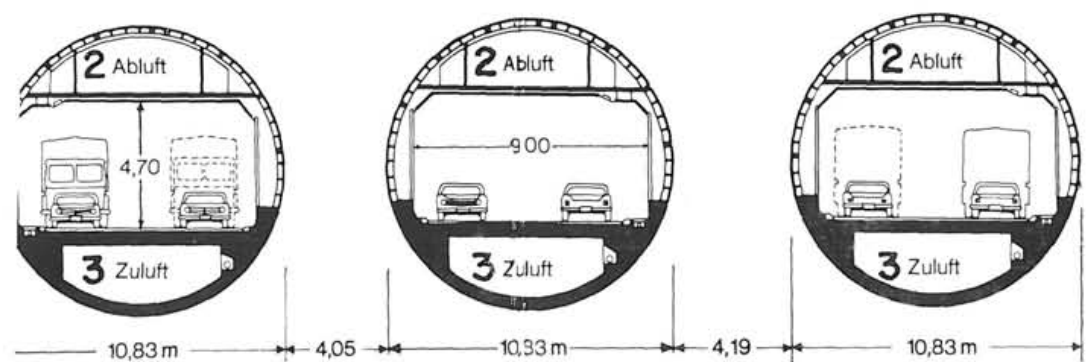

tramo 2

Zuerschnitt Baulos III offene Bauweise

5

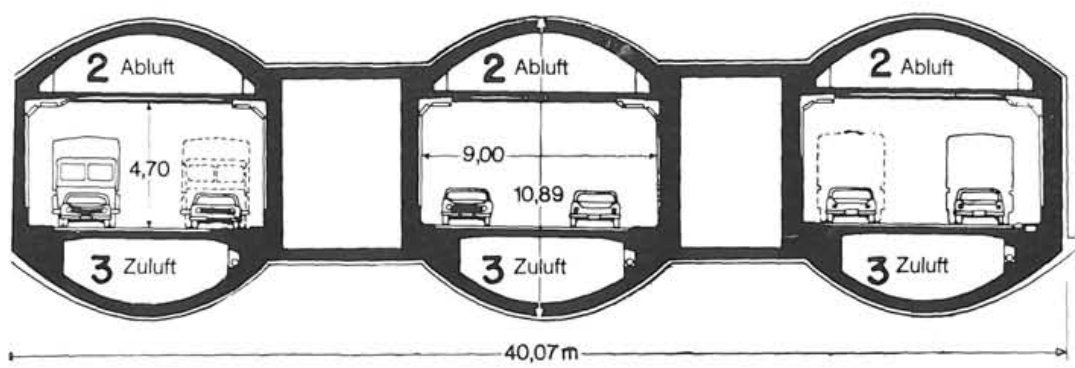

\section{tramo 3}

1. Tramo 1 (elementos sumergidos).

2. Salida de aire.

4. Tramo II (realizado con escudo).

5. Tramo III (sistema de construcción 


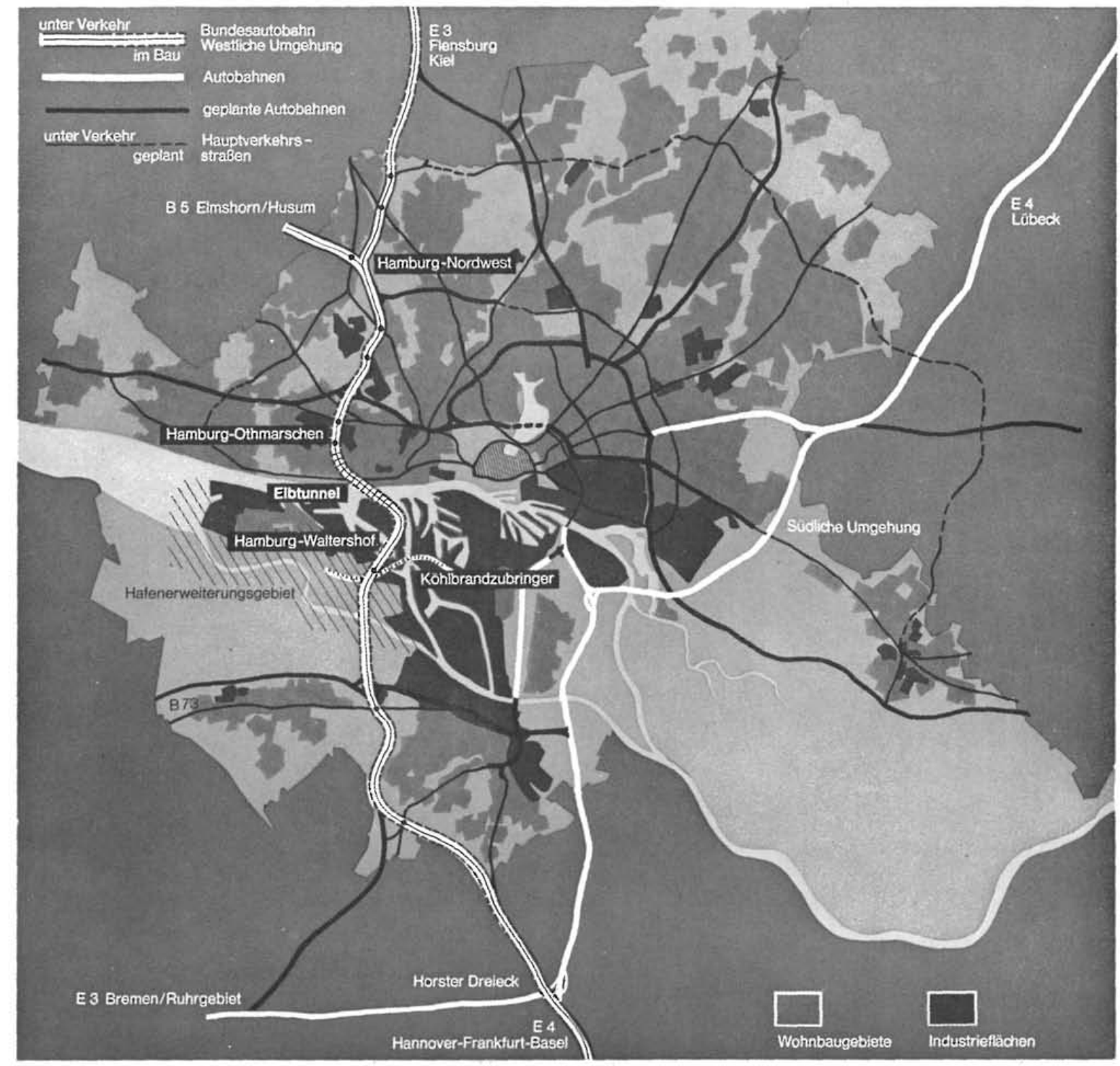

El aumento constante de la circulación rodada crea la necesidad de nuevas vías de tráfico, que, por lo general, precisan obras de ingeniería llenas de dificultades, como es el caso del túnel bajo el río Elba, en Hamburgo. Este túnel forma parte del tramo de circunvalación occidental de la ciudad, que, a su vez, se integra en la autopista federal Hamburgo-Flensburgo.

Para solucionar el obstáculo natural del río, se abandonó la primitiva idea de construir un puente. Este hubiera requerido una altura libre de paso cercana a los $70 \mathrm{~m}$ y rampas extraordinariamente largas y elevadas que habrian producido, aparte de complicadas conexiones con la red viaria de la ciudad, una alteración grave del paisaje urbano. Por ello se eligió la solución del túnel, dispuesto oblicuamente respecto a la corriente del agua, con lo que se respetaban así las condiciones urbanas.

\section{planta general}

Transporte inferior. En obra. En obra. Planificado.

5. Autovía del Estado, dirección oeste.

Autopista.

Autopista proyectada,
Lineas de transporte principales. 


\section{parque de prefabricación}

Esta importante obra tiene una longitud total de $3.325 \mathrm{~m}$, con un recorrido de $2.633 \mathrm{~m}$, en el que se utiliza una aireación especial, conseguida por medio de tres estaciones de ventilación y canales de alimentación y salida del aire viciado, repartidos a lo largo del recorrido.

Los trabajos de construcción del túnel, debido a su gran envergadura, se dividieron en tres lotes. El primero abarca dos tramos: el sector sur, de $800 \mathrm{~m}$ de longitud, formado por la estación de ventilación en aquella zona y las rampas de acceso; y el recorrido bajo el cauce del río. El segundo es un tramo de $1.113 \mathrm{~m}$ de largo, bajo el declive del Elba, y que incluye la estación central de ventilación en la orilla norte. Por último, el tercer tramo tiene una longitud de $325 \mathrm{~m}$, de los que 180 son de recorrido del túnel en zanja abierta, y 25 corresponden a la estación de ventilación norte.

En sección transversal el túnel está constituido por tres tubos, con dos carriles de circulación cada uno, utilizándose los dos tubos exteriores para tráfico en un solo sentido, y el central en los dos. En el recorrido bajo el cauce del río los tres tubos, junto con sus canales de ventilación, se reunen en una pieza única de sección rectangular, a la que se dio la
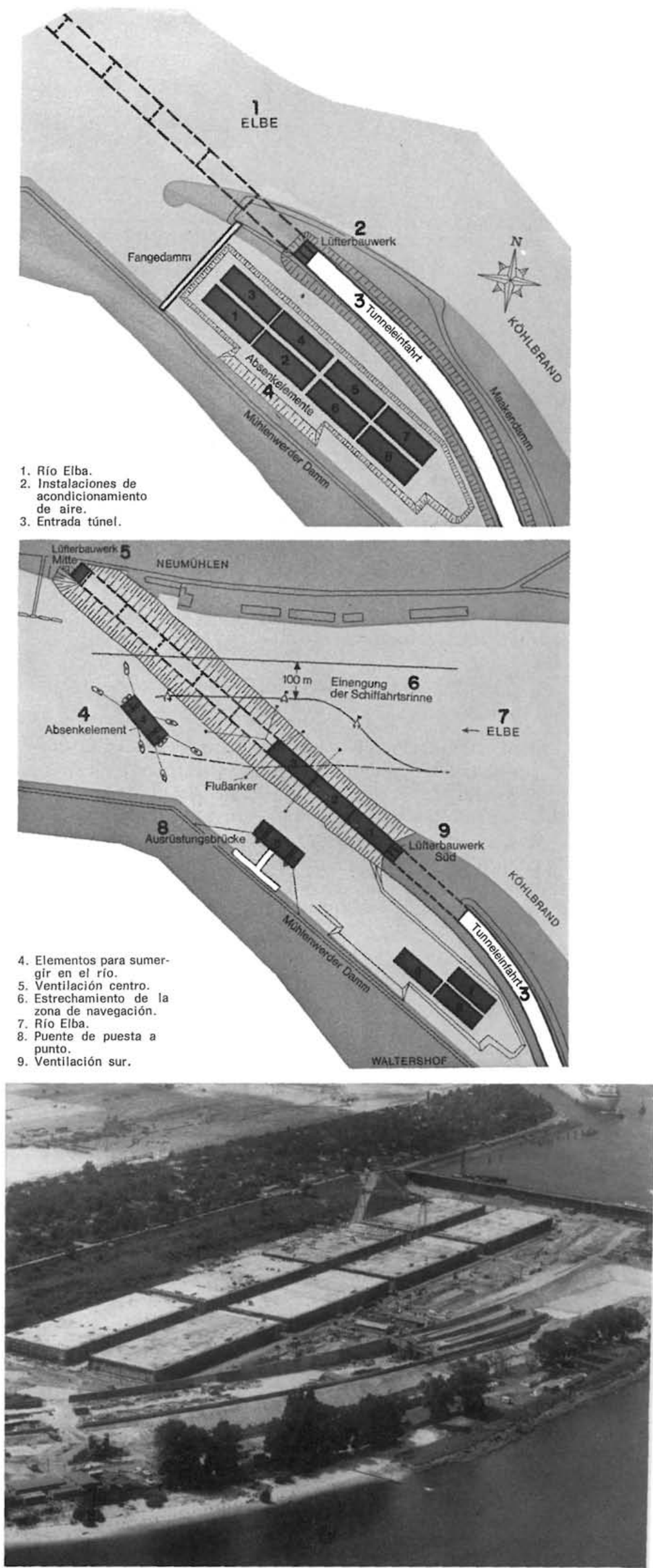


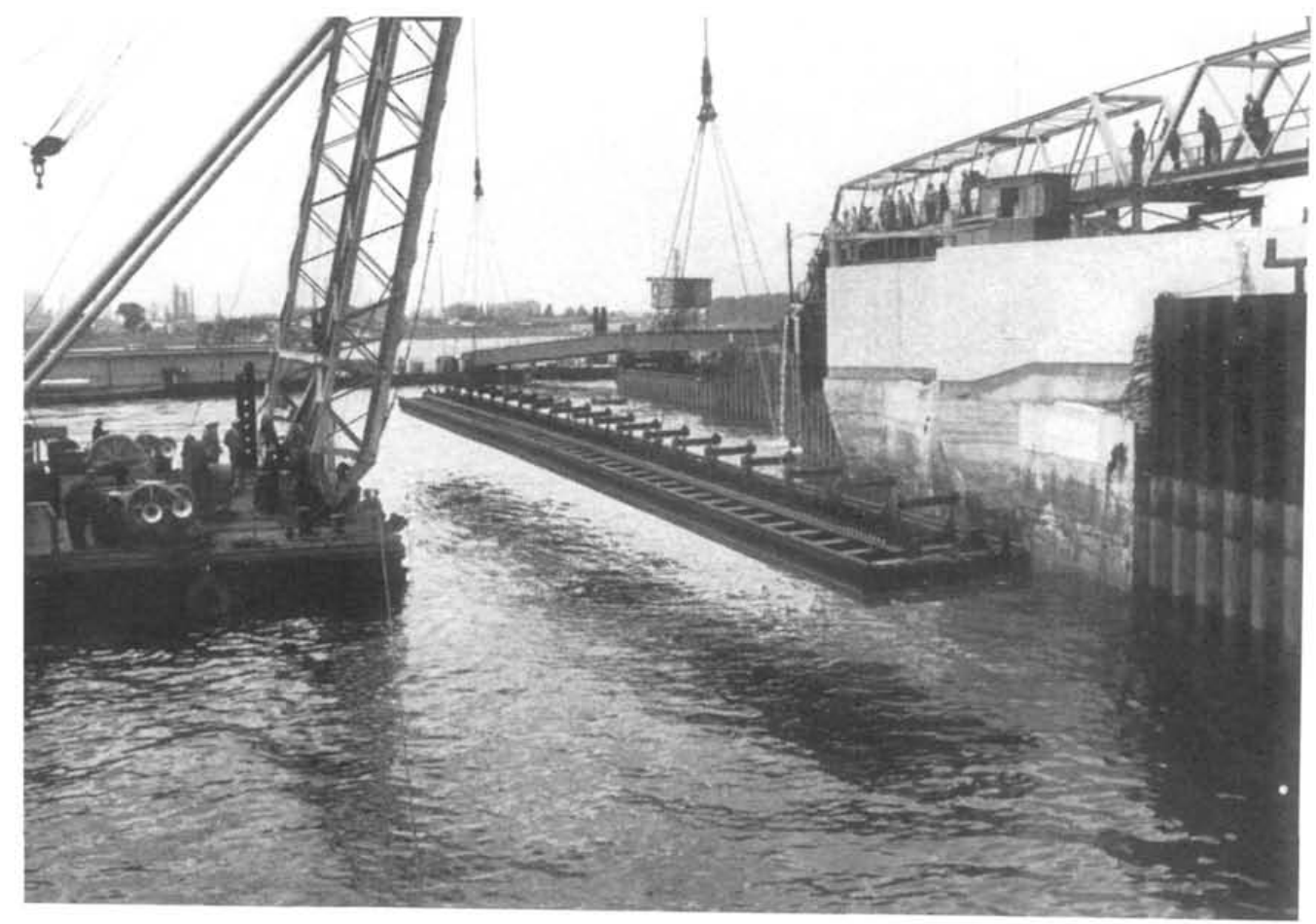

menor altura posible. Cada pieza tiene $132 \mathrm{~m}$ de largo, 41,70 m de ancho y $8,40 \mathrm{~m}$ de alto, con las paredes y el fondo revestidos herméticamente en chapa de acero de $6 \mathrm{~mm}$ de grosor. En un dique seco de las proximidades se construyeron ocho elementos de estas características, que, una vez unidos, daban la longitud completa del tramo. Después de terminados los ocho elementos, se cerraron por sus extremos con mamparas especiales, llenándolos de agua, a modo de lastre, para que, al quitar el dique e inundar la zona, quedasen en el fondo.

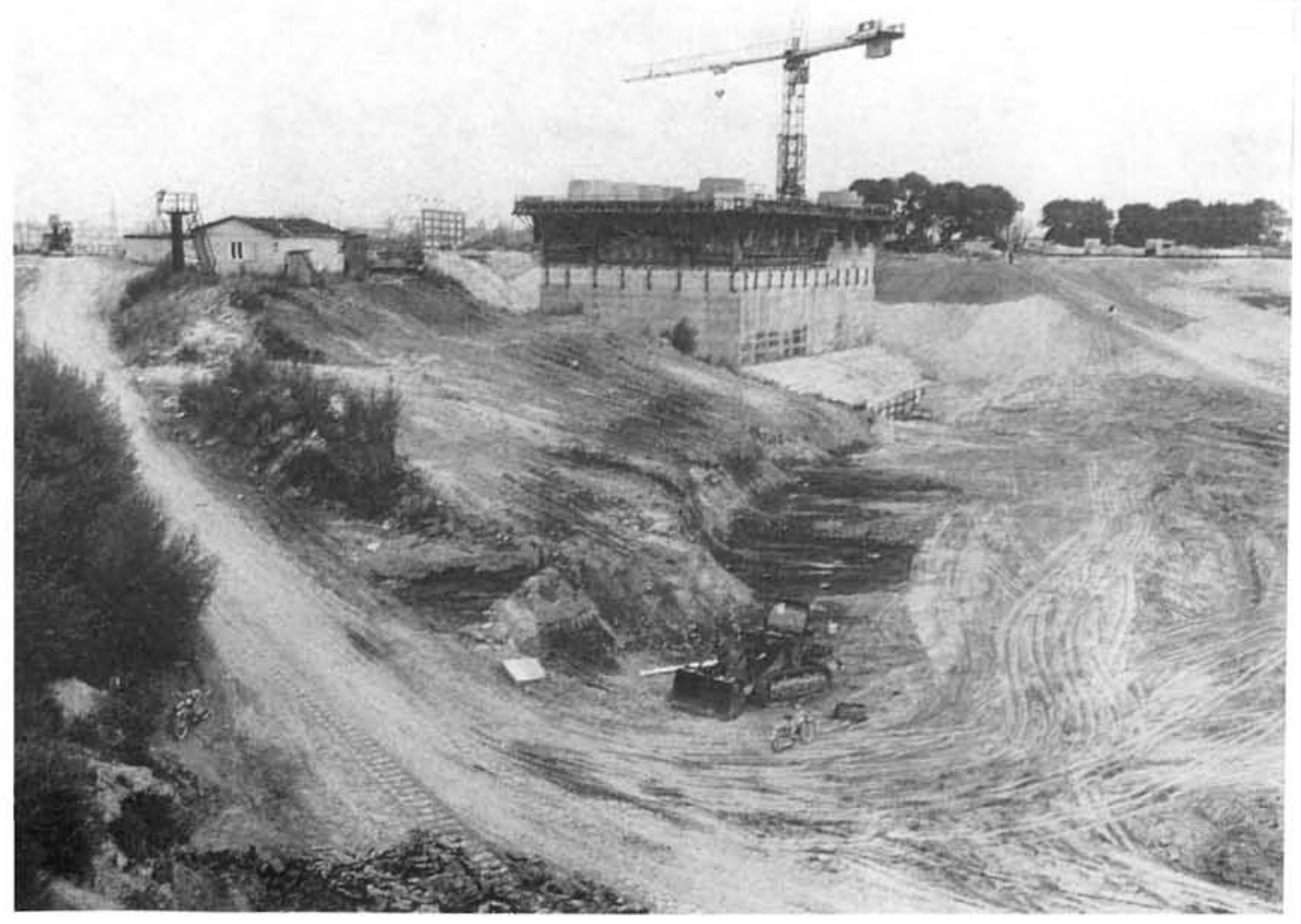




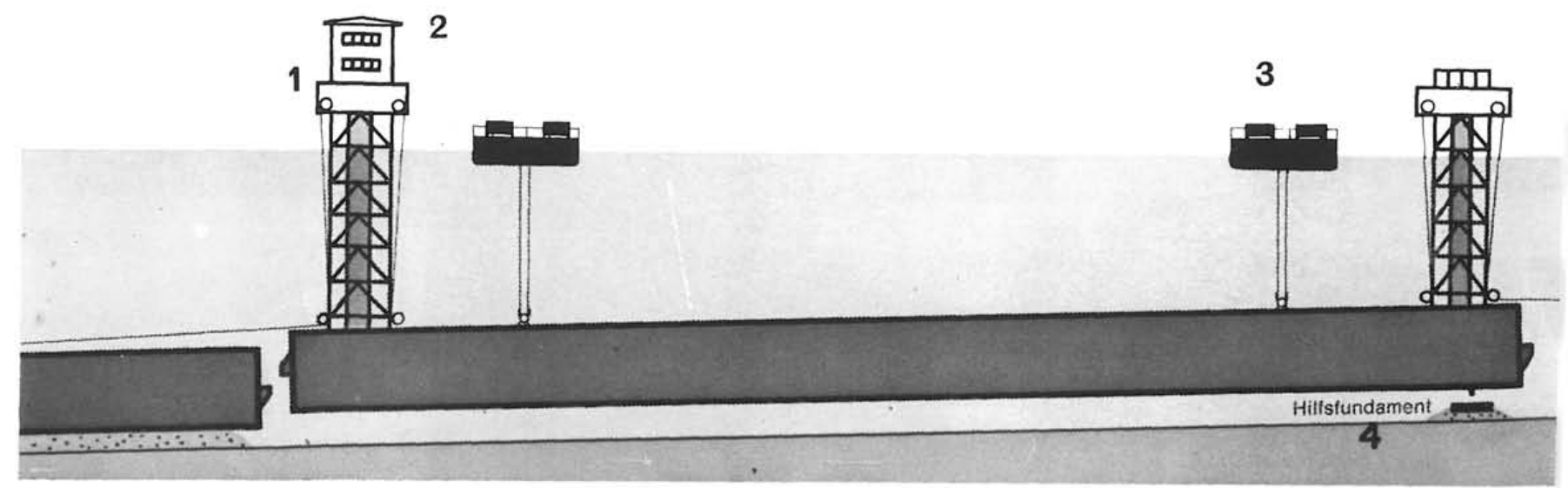

Al mismo tiempo se realizó una zanja en el fondo del río, zanja que fue dragada posteriormente, y en la que se colocaron unas placas de asiento, de $1 \mathrm{~m}$ de espesor, que servirian de apoyo a los distintos elementos. También se excavó el terreno delante de la estación de ventilación sur, edificio de hormigón armado, de aproximadamente $30 \mathrm{~m}$ de altura, que aloja los ventiladores de inyección y salida de aire.

El siguiente paso en el proceso fue achicar el agua del primer elemento $y$ hacerlo flotar, para después, mediante remolcadores, colocarlo sobre la vertical del lugar en que sería sumergido, anclándolo al lecho del río. Va provisto de dos torres de orienta-
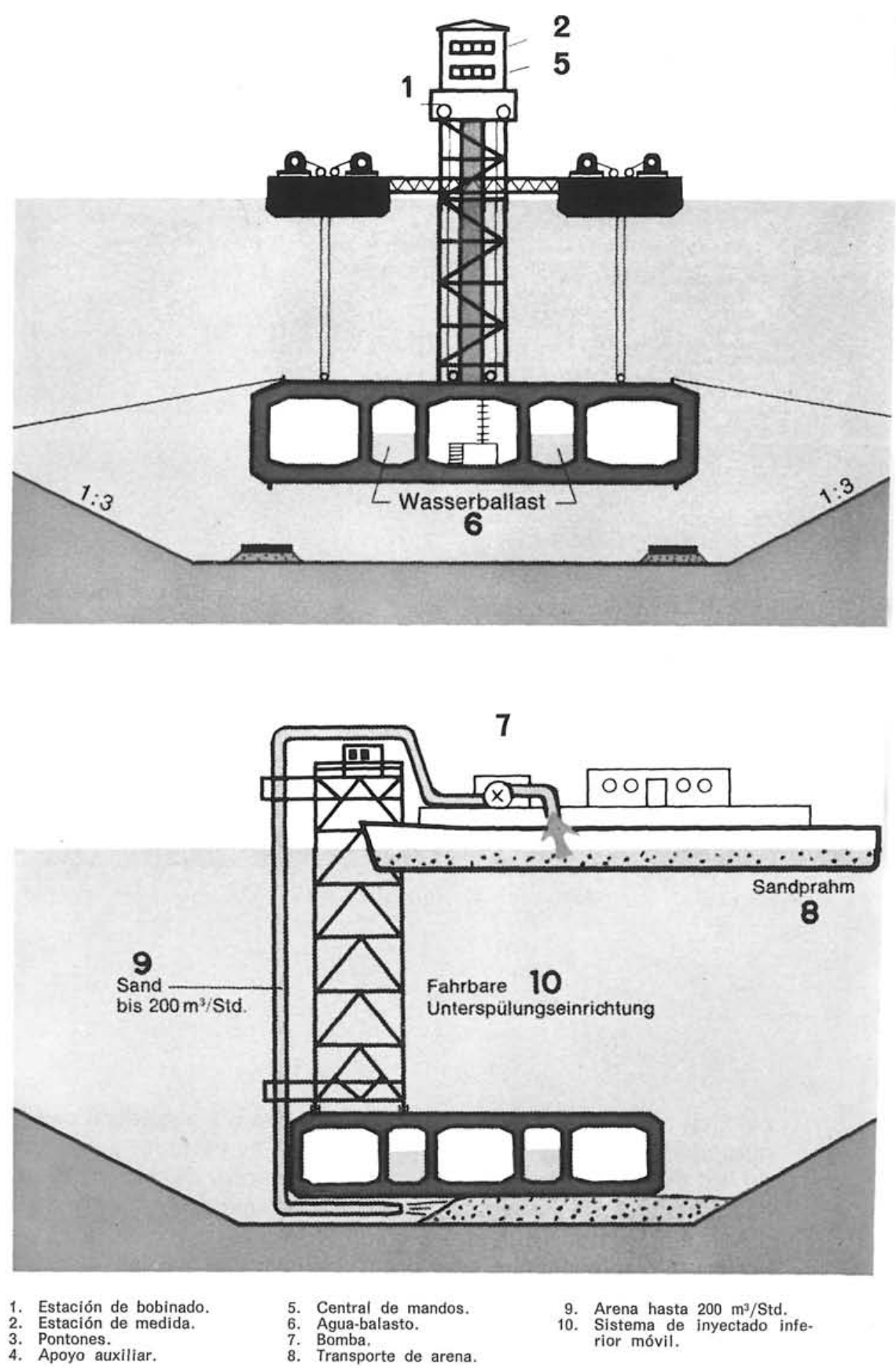

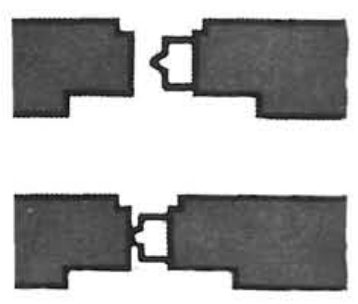

2
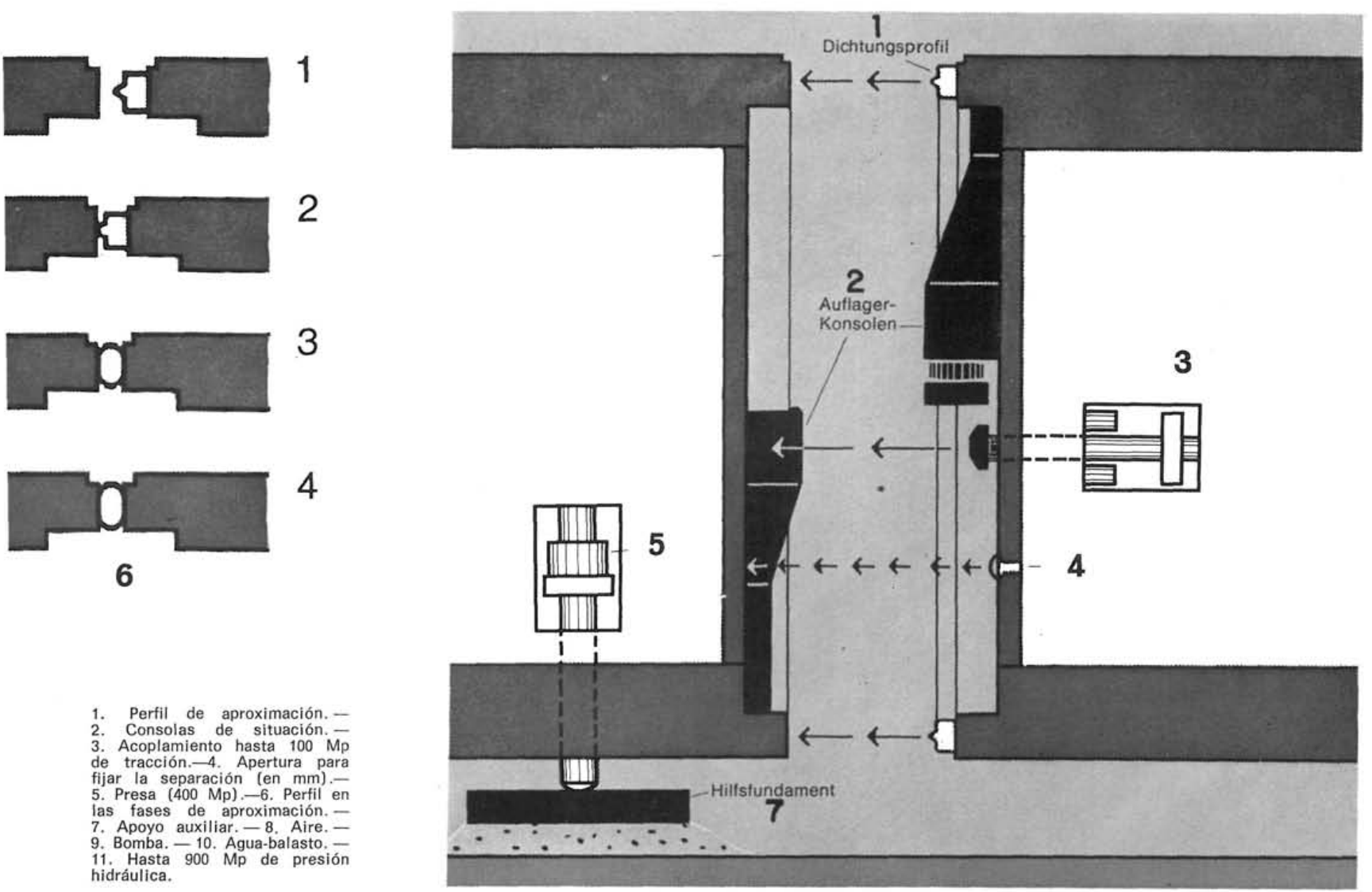

3

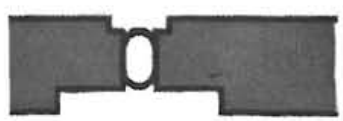

4

6

1. Perfil de aproximación. 2. Consolas de situación. $-\overline{-}$ de tracción.-4. Apertura para fijar la separación (en mm).5. Presa $(400 \mathrm{Mp})$. -6. Perfil en las fases de aproximación. 7. Apoyo auxiliar. -8 . Aire. 9. Bomba. - 10. Agua-balasto. 11. Hasta $900 \mathrm{Mp}$ de presión
hidráulica.

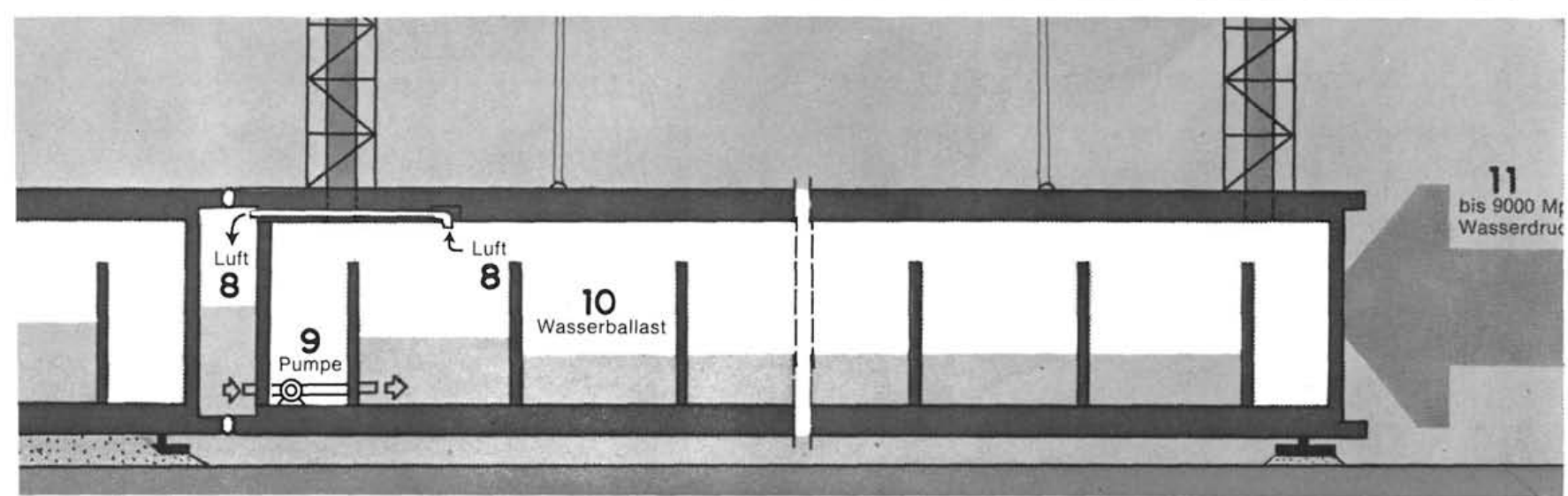

ción, en cada una de las cuales se encuentra un pozo de acceso al interior del elemento, de forma que puede ser recorrido, incluso una vez sumergido, a una presión normal de aire. Desde una de las torres se dirige la inmersión, comprobándose constantemente la posición mediante sondas acústicas. El hundimiento se efectúa inundando los canales de ventilación, y, por medio de un sistema de cables, accionados desde las torres, se mantiene el elemento en posición horizontal, colocándolo, con gran precisión, sobre las placas de asiento del fondo. La separación de $1 \mathrm{~m}$ que queda entre la base del elemento y la superficie dragada del lecho del río, se rellena con una mezcla de agua y arena, de granulometría uniforme, bombeada desde una gabarra por un tubo que pasa por una de las torres. Este elemento de inyección termina en un 
. De 38,47 hasta $39,08 \mathrm{~m}$. De 8,86 hasta $0,88 \mathrm{~m}$ Relleno de arena. Echadizo.

. Arcilla. gonados in situ.

Turba

Balasto

Drenaje.

Hormigón de seguridad.

Relleno de asfalto.

Salida de aire.

Entrada de aire.

Conducto central.

Conducto este.

Hormigón relleno.

Hormigón B-450.

Revestimiento con cha

pa de acero.

nio.

1
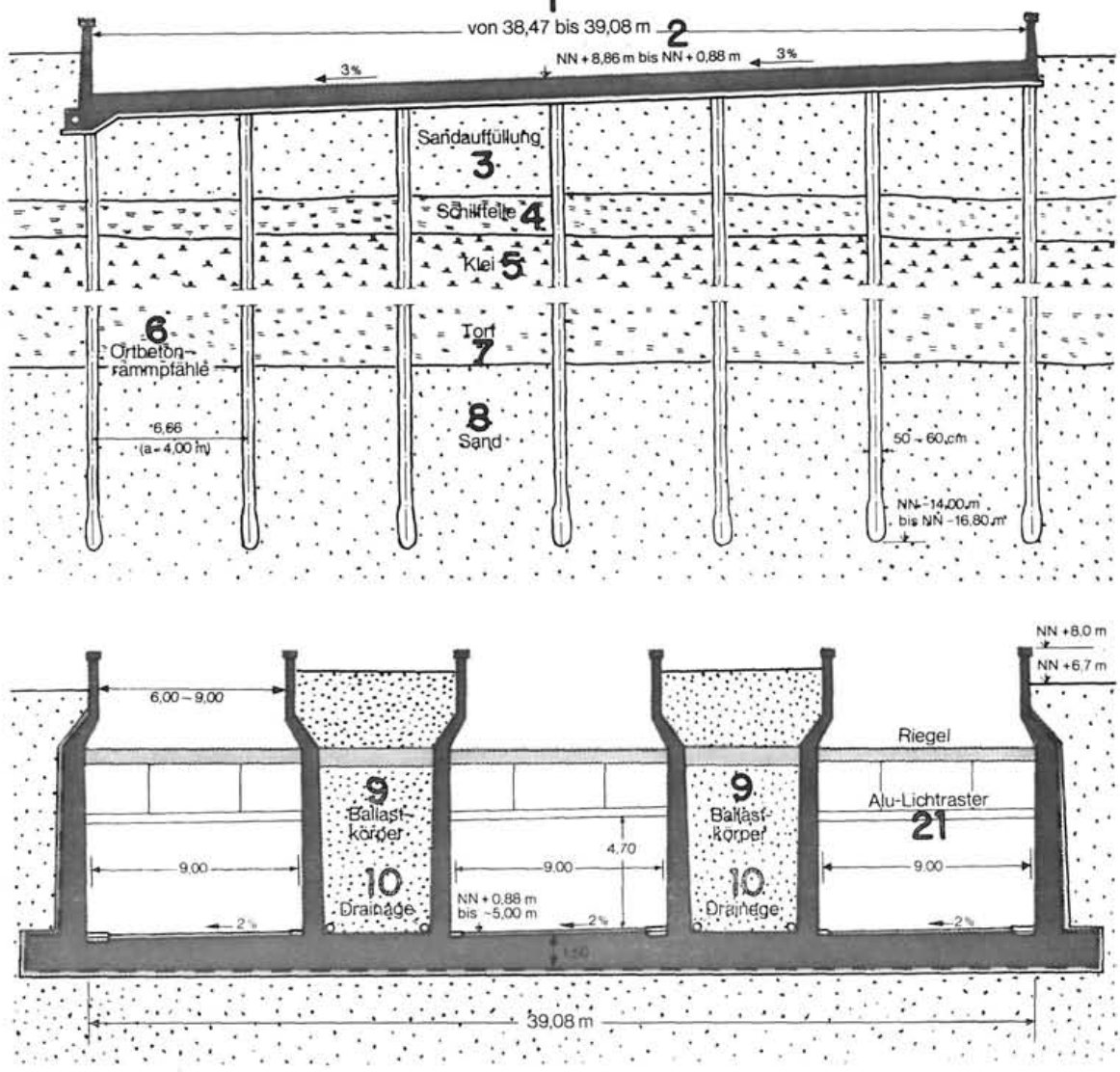

12

11

se Abdichtung

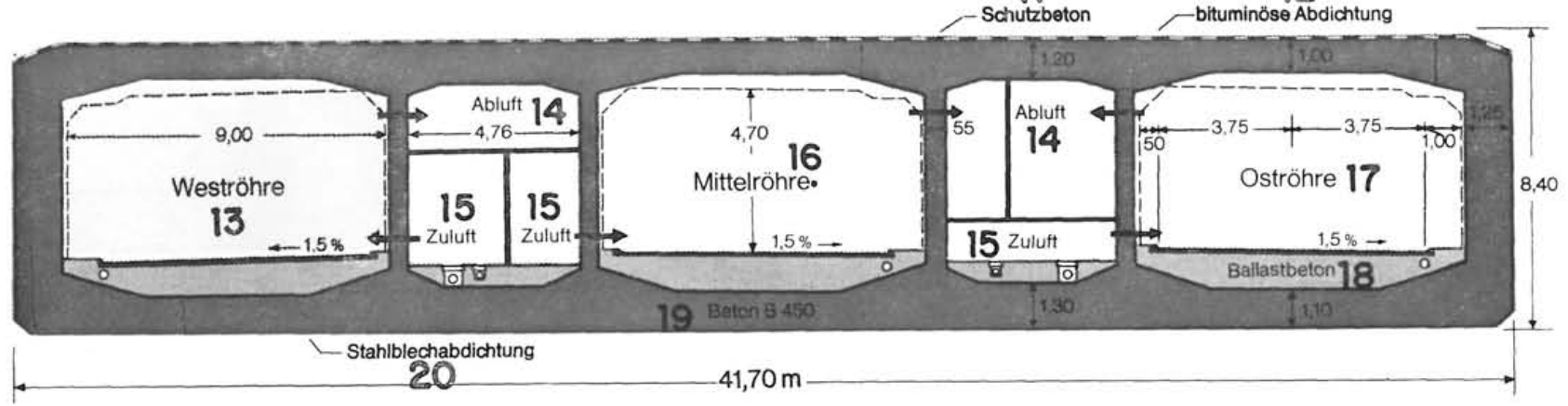

brazo horizontal, provisto de una tobera en su extremo, que puede moverse bajo el elemento para llegar a todos los puntos y rellenar perfectamente todo el espacio. El agua de lavado sobrante se elimina por medio de tubos de aspiración, y según el porcentaje de arena contenida en el agua recuperada puede saberse cuándo queda terminado el proceso en la zona que se trabaja, y pasar la torre a otro lugar. Los siguientes elementos se van colocando, por el mismo procedimiento, al ritmo de uno cada dos meses.

La inmersión de los elementos del túnel pudo llevarse a cabo sin crear grandes dificultades en la navegación fluvial. Desde el punto de vista técnico, el procedimiento hidráulico seguido 
1. Canal de salida de aire.

2. Iluminación.

3. Salida de aire 4. Cielorraso absorbente de
ruido.

5. Eje del túnel.

6. Eje del pavimento.

7. Entrada de aire.

8. Drenaje de agua.

9. Canal entrada de aire.
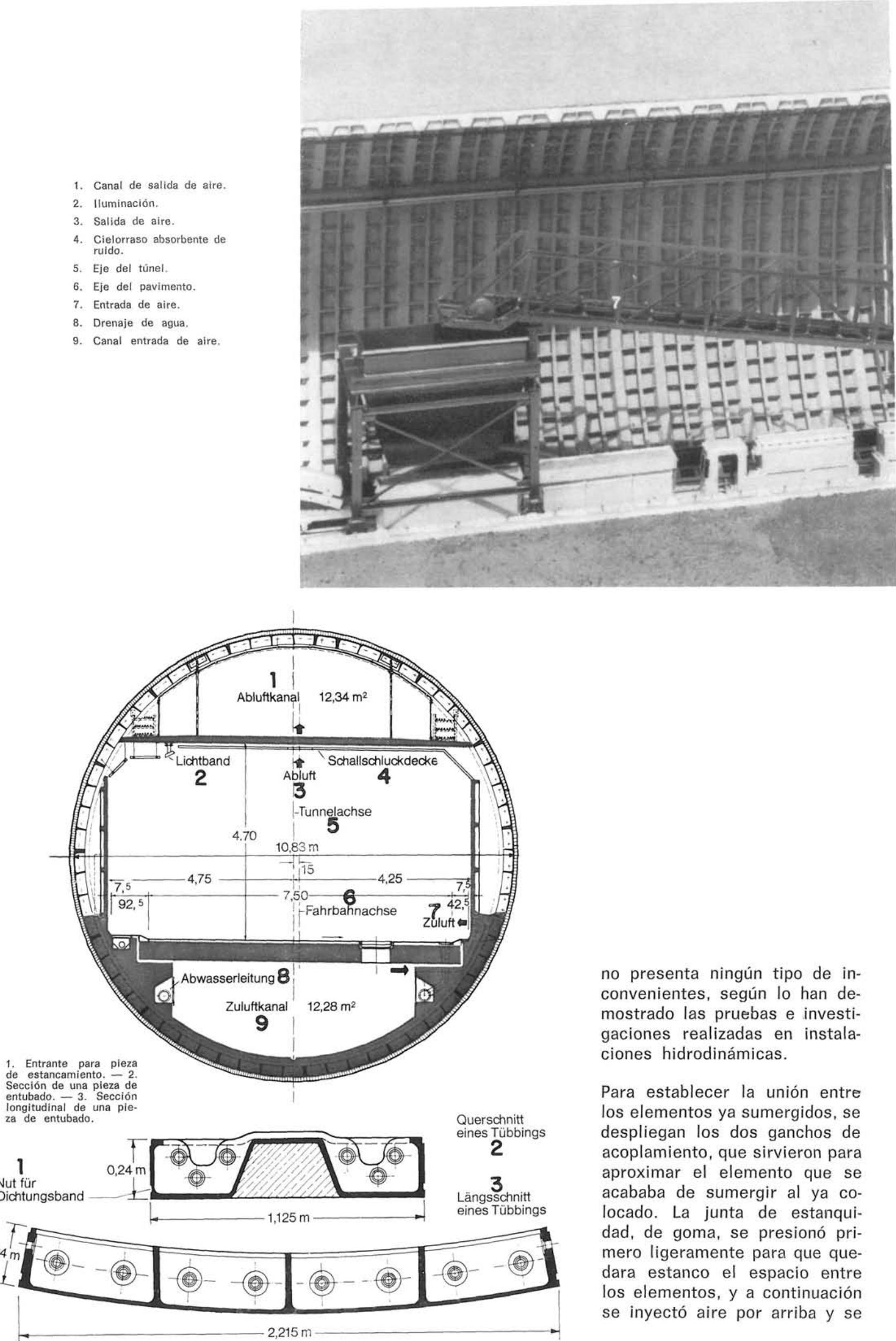

no presenta ningún tipo de inconvenientes, según lo han demostrado las pruebas e investigaciones realizadas en instalaciones hidrodinámicas.

Para establecer la unión entre los elementos ya sumergidos, se despliegan los dos ganchos de acoplamiento, que sirvieron para aproximar el elemento que se acababa de sumergir al ya colocado. La junta de estanquidad, de goma, se presionó primero ligeramente para que quedara estanco el espacio entre los elementos, y a continuación se inyectó aire por arriba y se 


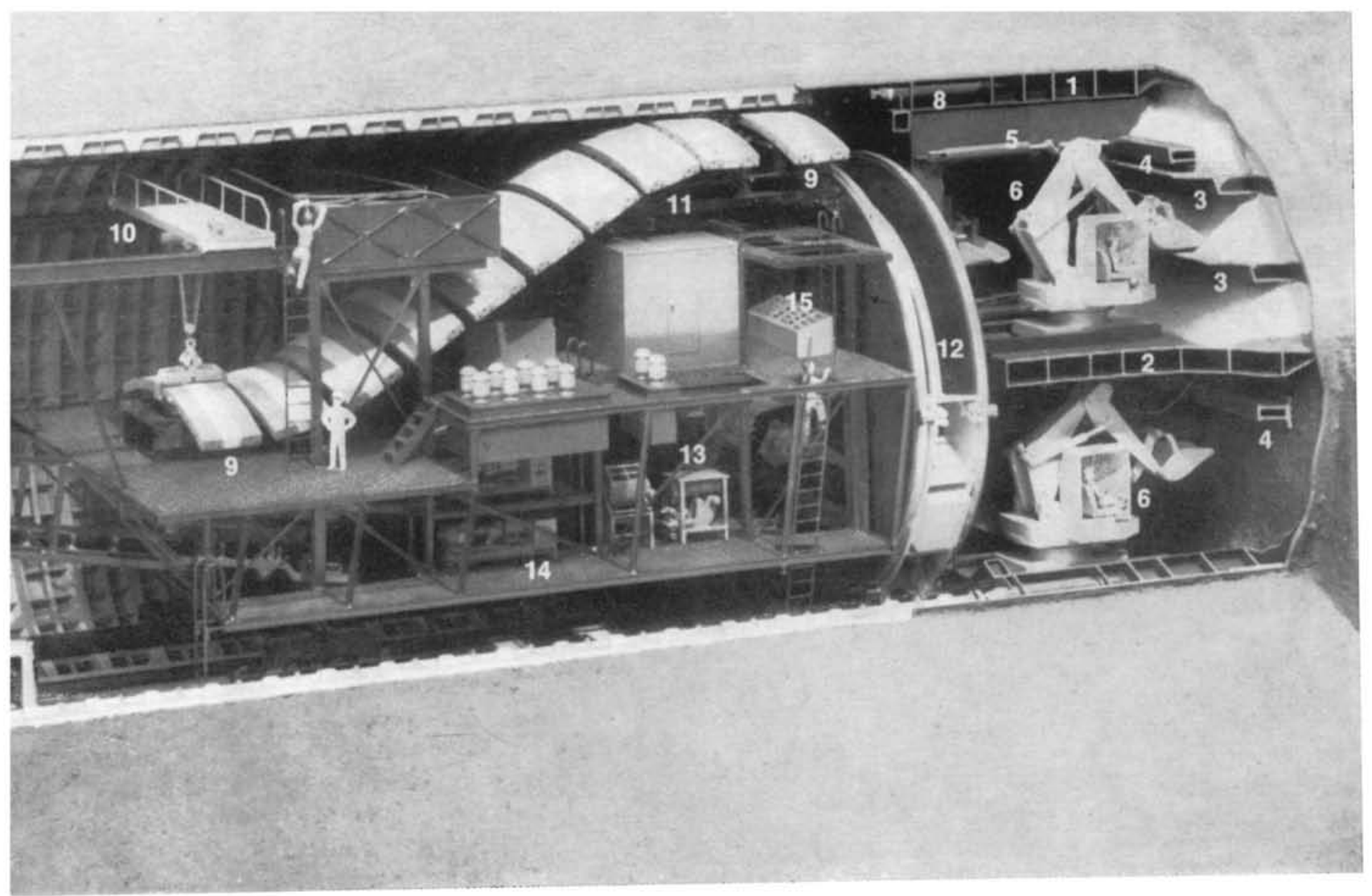

bombeó agua por abajo, produciéndose una presión desde el exterior que ajustó fuertemente los elementos, colocándose entonces, desde el interior, una junta de goma definitiva. La unión del último elemento con el edificio central de ventilación se cerró desde el exterior, con la ayuda de buzos y hombres rana, se vació mediante bombeo $y$, finalmente, se impermeabilizó desde dentro de forma definitiva. Esta fase de la obra concluyó al cubrir todo el tramo con el material resultante de la excavación anterior y al sustituir el agua de lastre por hormigón.

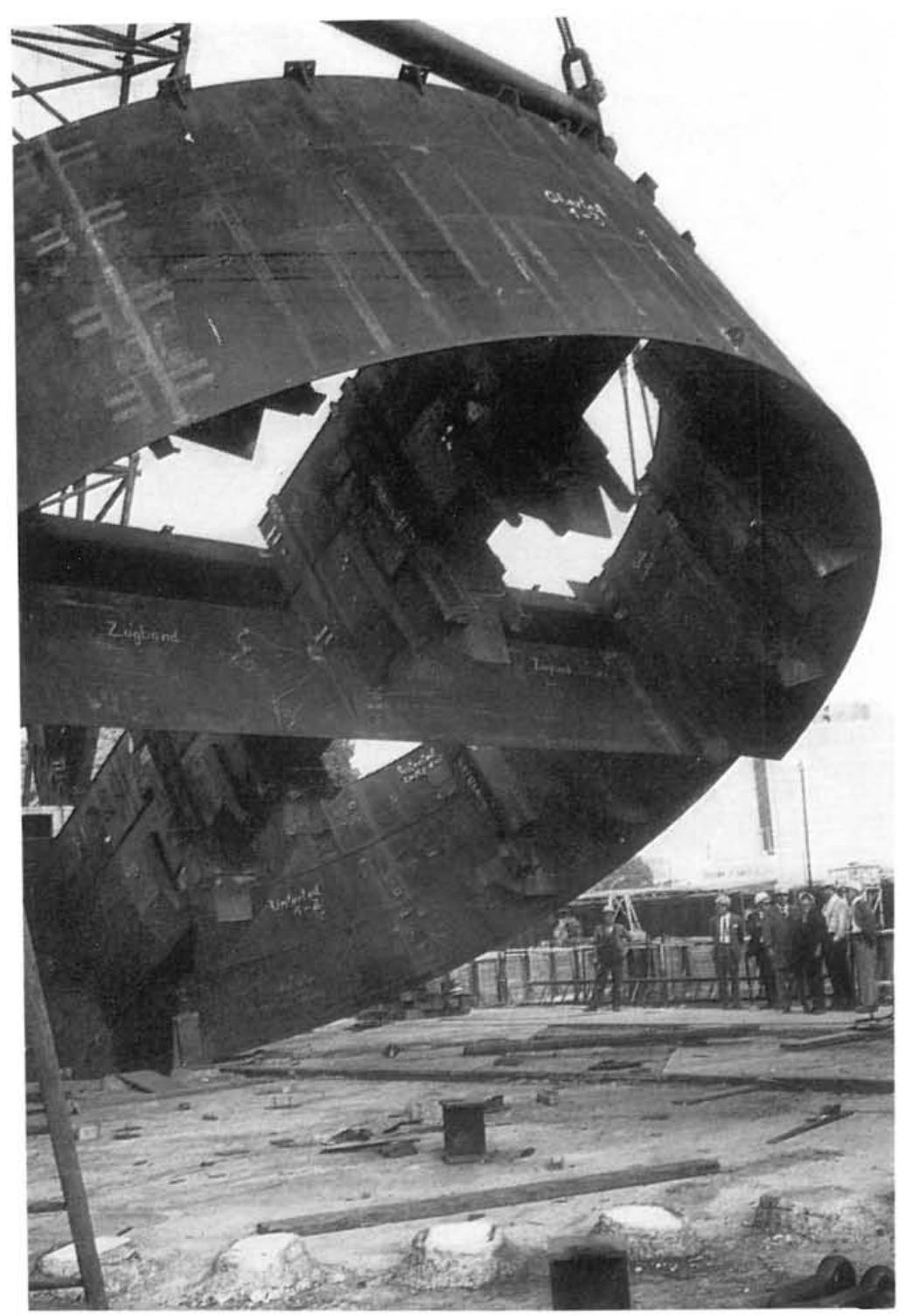




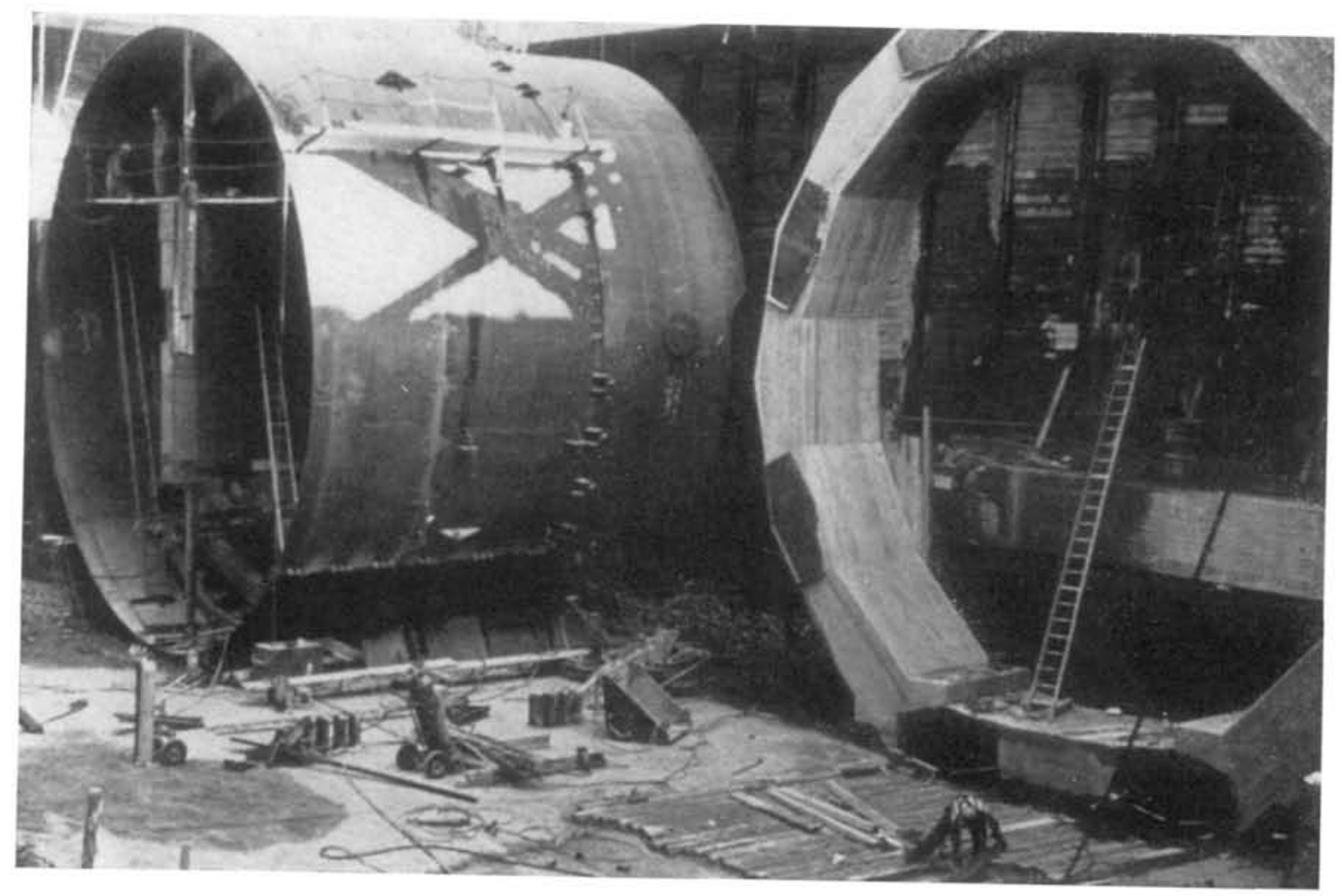

En la segunda fase de construcción, bajo el declive del río, se perforó utilizando el método de avance por escudos, empotrando, mediante prensas, un tubo de acero - escudo- en la roca. Con la protección de este escudo se iba arrancando la tierra del fondo

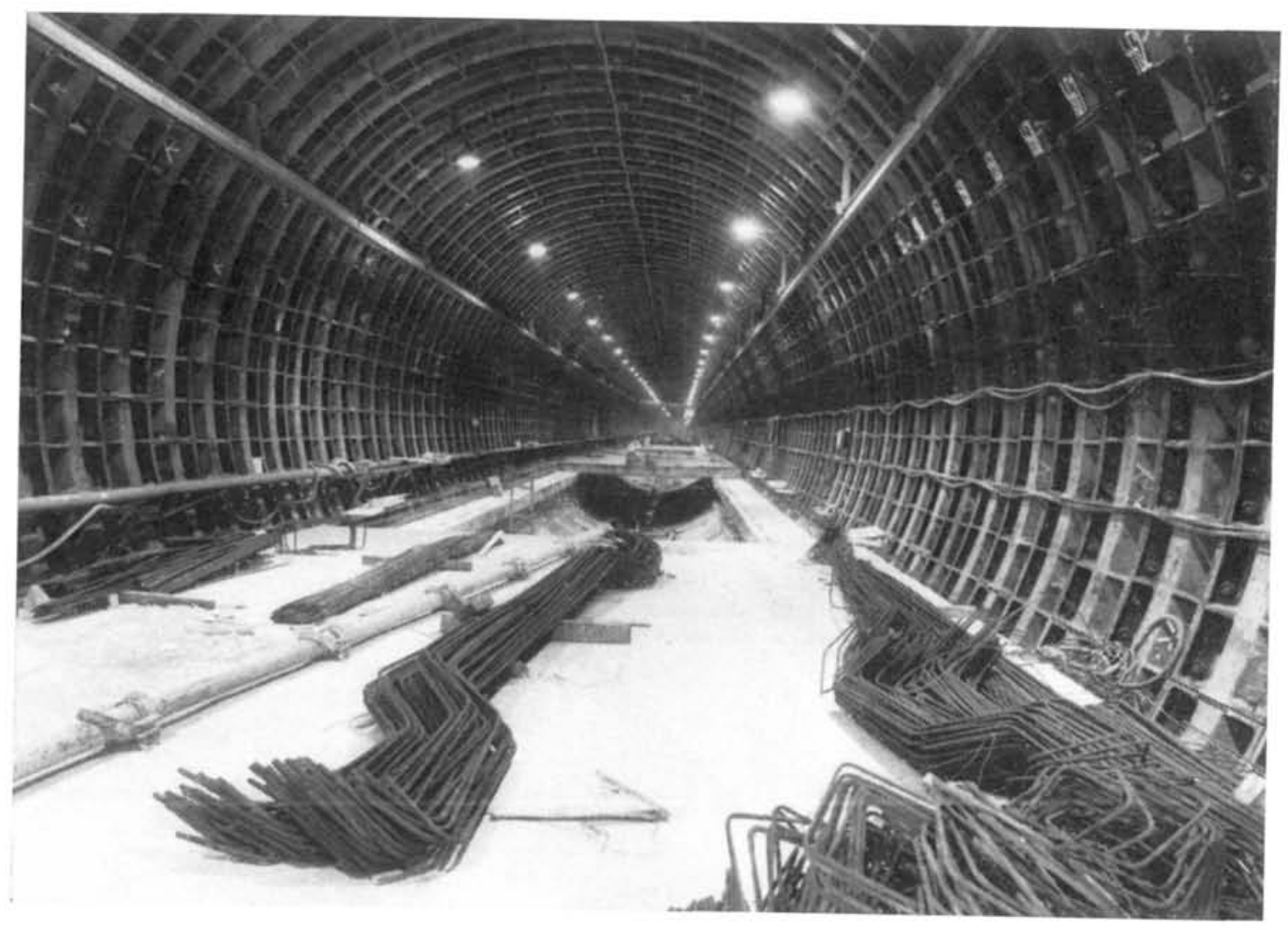




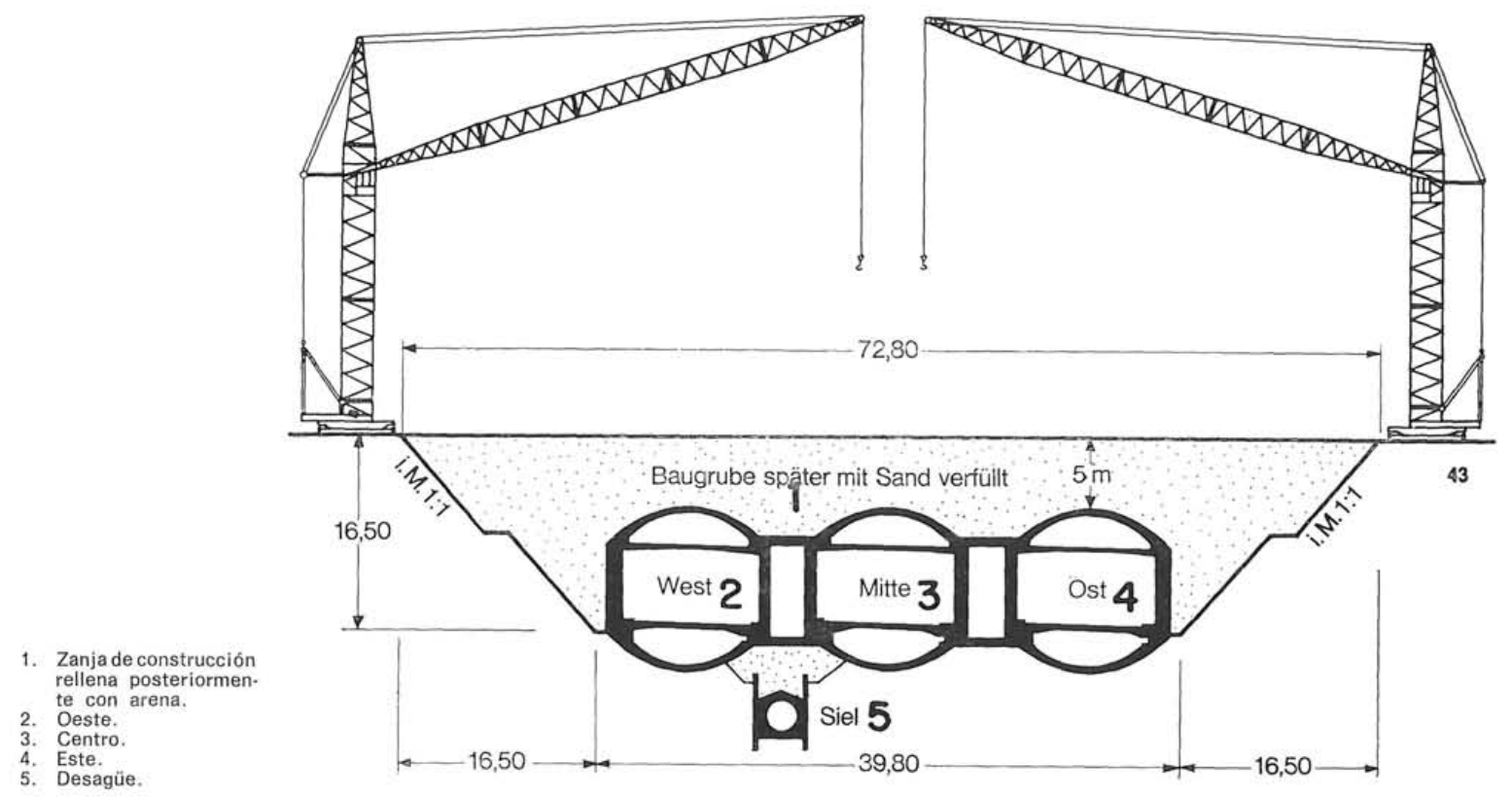

del túnel con auxilio de potentes excavadoras hidráulicas y cargándola sobre cintas transportadoras para su evacuación. Una vez terminados los trabajos de avance se procedió al hormigonado del hueco, para el posterior equipamiento del túnel y construcción de las calzadas.

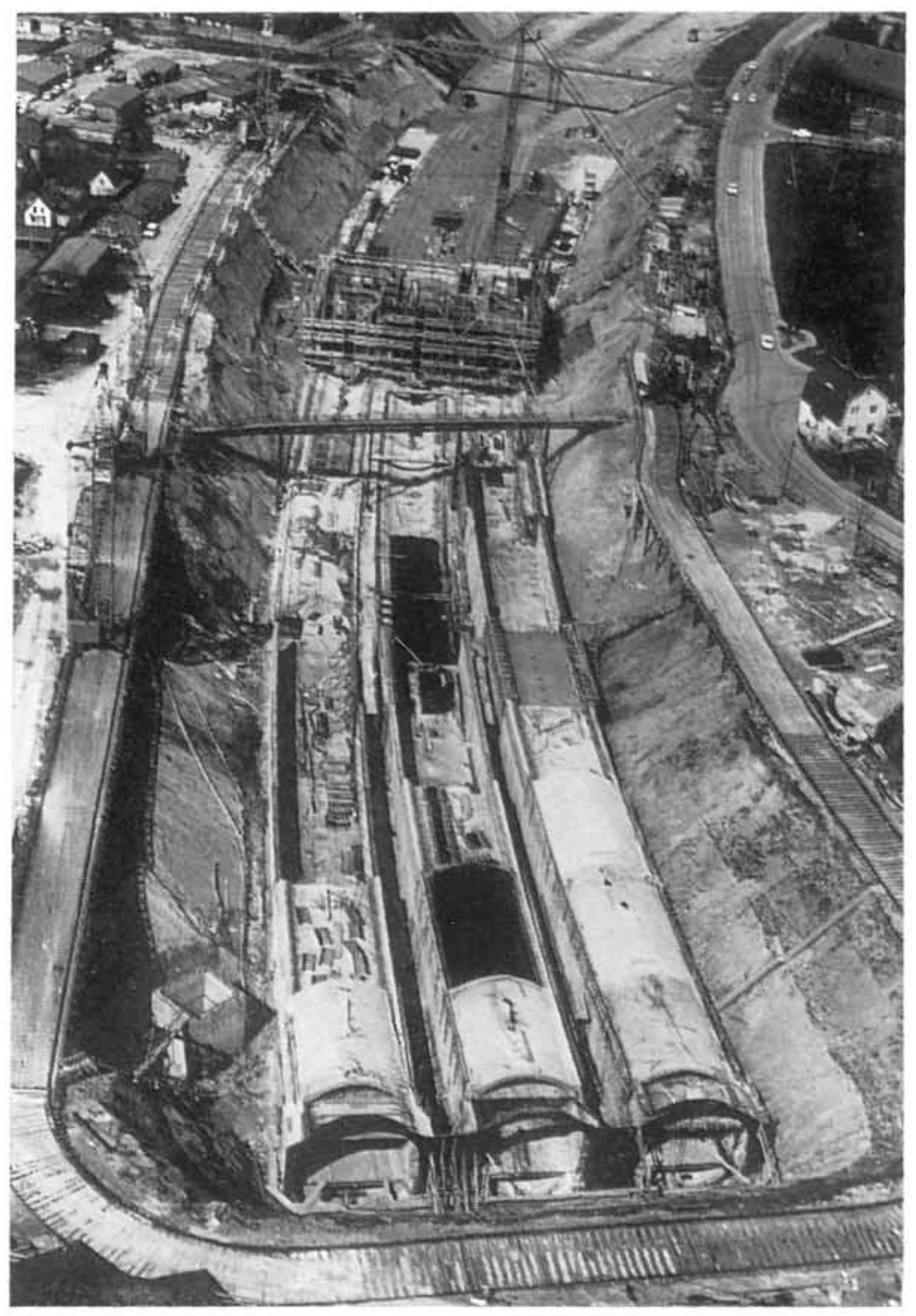


Los dispositivos para la puesta en marcha de la maquinaria se montaron en el suelo del túnel, utilizándose una moderna construcción, de tal modo configurada, que podia volver a utilizarse en cada uno de los lugares de perforación.

Las obras de hormigón armado para la estación central de ventilación se iniciaron antes de efectuarse el montaje del escudo, preparando el fondo que, simultáneamente, sirve de cimentación y de refuerzo del lugar de arranque de la excavación. Una vez que el escudo abandona el punto de partida, se procede a la construcción del edificio, impermeabilizando la parte inferior con chapa de acero de $6 \mathrm{~mm}$ y la superior con mampostería y alquitrán. Terminada esta obra se dragó por el costado del río con el fin de que el último elemento (de los ocho que componen el tramo bajo el cauce) pudiera ser colocado y unido al edificio de la estación de ventilación. Después de esta operación, se cubrió con tierra por el lado del agua.

El tramo de túnel de la tercera fase se realizó con las entradas y salidas de aire, de los tres conductos, en forma de bóvedas parabólicas, lo que permite una ventajosa admisión de las elevadas cargas producidas por la tierra y, por consiguiente, reducir la dimensión de las secciones. Los momentos motivados por la presión de las tierras sólo los reciben dos de las seis paredes del túnel, lo cual simplificó notablemente la impermeabilización.

La zona final del recorrido en este tramo tiene poca profundidad y las edificaciones dispuestas en superficie y muy espaciadas, lo que permitió la construcción de los tubos a cielo abierto. La zanja excavada, de una profundidad de $17 \mathrm{~m}$, se llevó a cabo en cuatro sectores, empleando dragas hidráulicas. En el curso de la excavación se tropezó con una capa de turba que alcanzaba hasta $7 \mathrm{~m}$ por debajo de la cimentación prevista, en una extensión de $27 \mathrm{~m}$, lo que obligó a hincar pilotes, en número de 472 , para sostener una placa de hormigón armado que sirviera

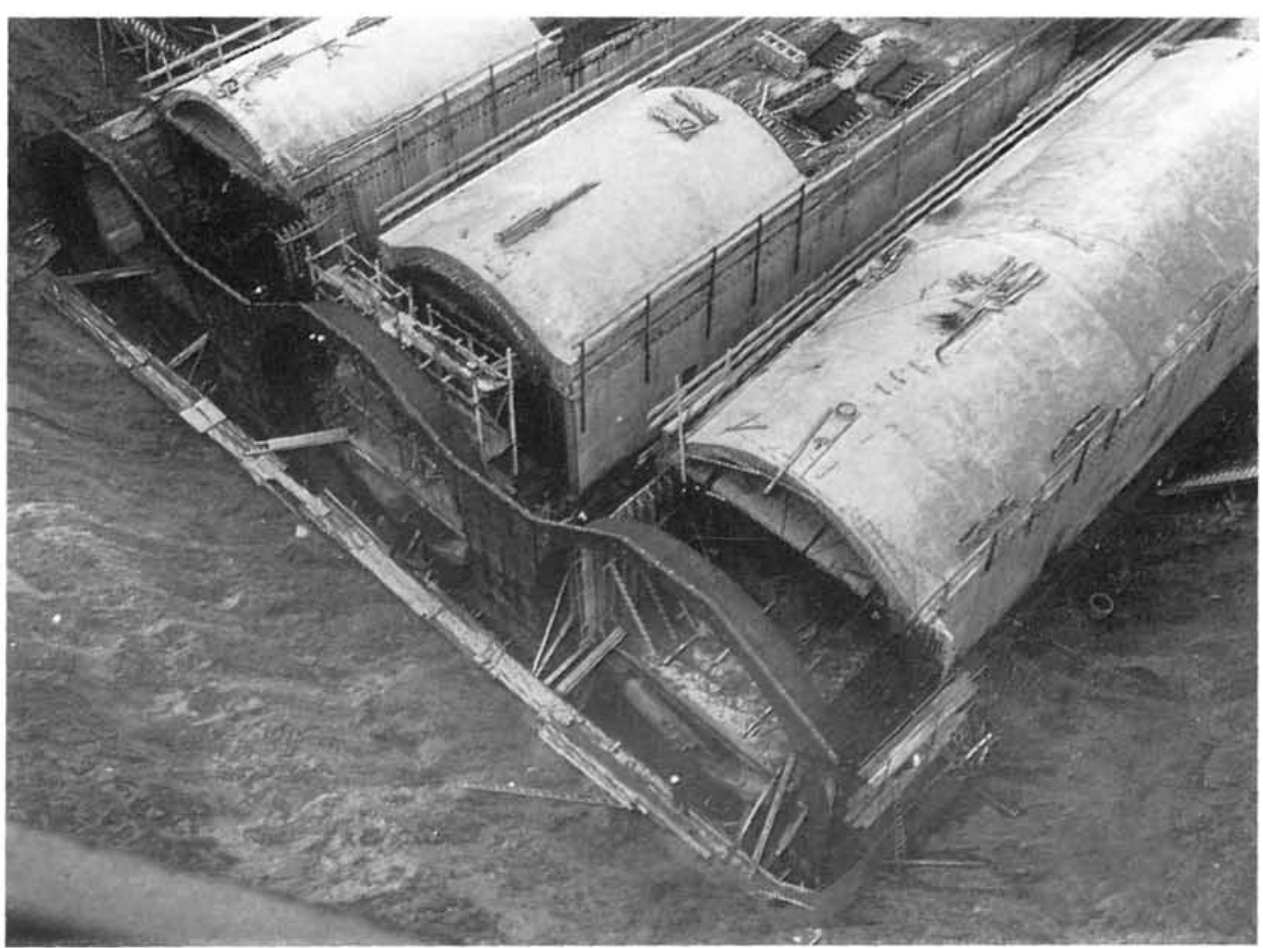



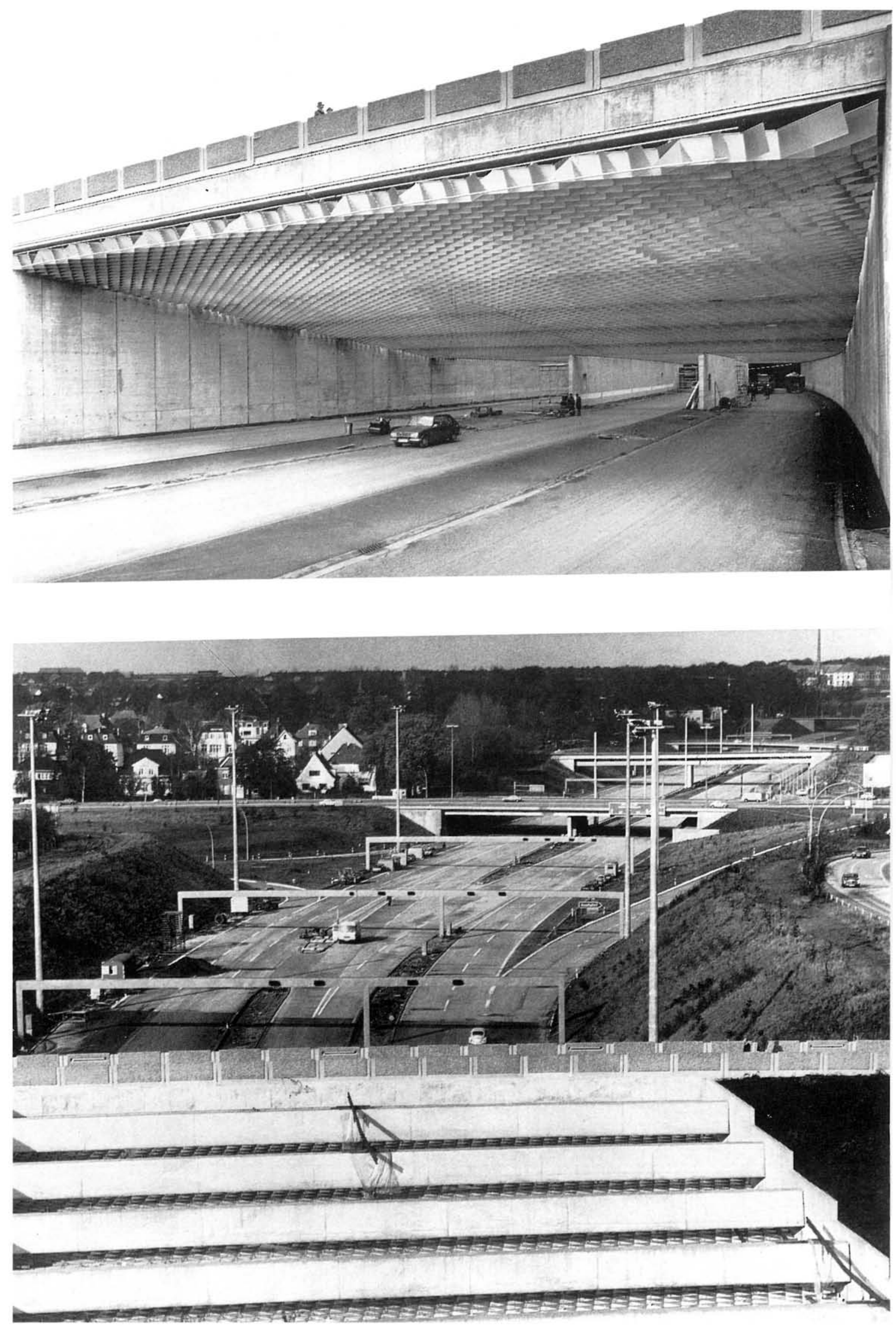
de apoyo a los tubos. Estos últimos se fabricaron empleando elementos de revestimiento de gran tamaño, que podían transportarse, con la ayuda de grúas-torre giratorias, por el borde de la zanja hasta el lugar del ensamble.

La estación norte de ventilación, de $35 \mathrm{~m}$ de altura por encima de la cimentación, sirve para dar salida al aire viciado de la mitad del recorrido y para inyectar aire puro. Desde el mismo edificio se controla el sistema y regulación de toda la obra, que comprende: medidores de intensidad de tráfico, circuito cerrado de televisión, indicadores de preferencia de paso, semáforos, altavoces, y hornacinas en la pared, distanciadas $100 \mathrm{~m}$ unas de otras, con teléfono de emergencia, avisadores de incendios y extintores.

El revestimiento interior del tubo está formado por un zócalo de $70 \mathrm{~cm}$ de alto, con losetas cerámicas de colores claros, y un techo acondicionador acústico, de color oscuro. La calzada se terminó con una capa de $7,5 \mathrm{~cm}$ de alquitrán, vertido directamente sobre la base de hormigón. Para la iluminación del túnel se ha previsto, en cada uno de los tubos, una banda ininterrumpida de luces que se refuerza progresivamente en una longitud de $200 \mathrm{~m}$ en ambos accesos, mediante tubos fluorescentes adicionales, para así adaptarla a la luz exterior, durante el dia, y conseguir una acomodación gradual de la visión.

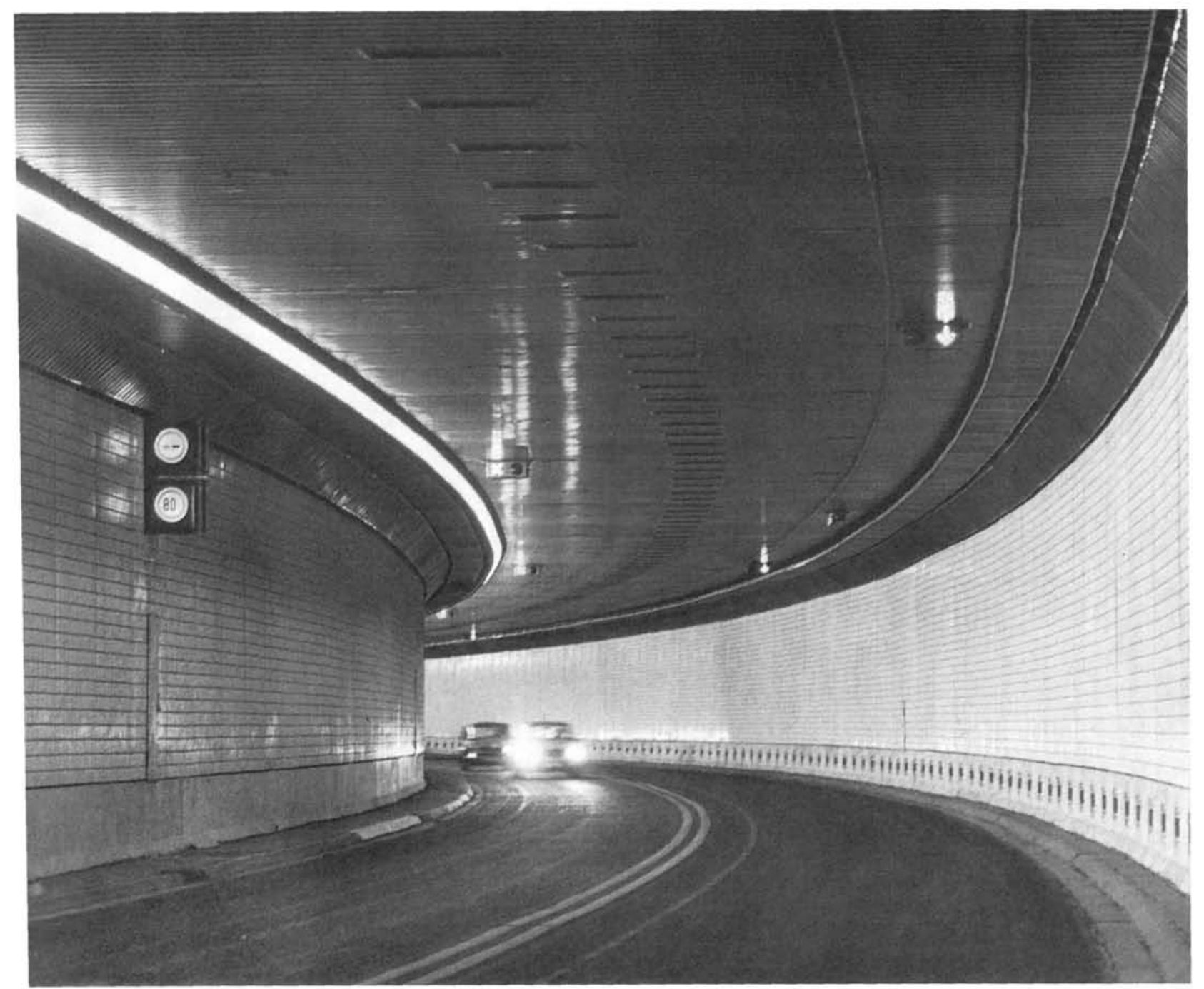


El río Elba constituye una arteria vital para la ciudad de Hamburgo, pero limitaba desde siempre el tráfico entre las partes norte y sur de la población, frenando el desarrollo en el núcleo del puerto. Este túnel no constituye sólo una parte importante de la red internacional y nacional de tráfico a larga distancia, sino que une con eficacia los núcleos urbanos de la ciudad, liberando a las calles del tráfico y descongestionando los cruces por encima del agua, como en el caso del puente al norte del Elba.

\section{résumé}

Tunnel sous l'Elbe - Hambourg République fédérale d'Allemagne

Cet important ouvrage, construit pour résoudre le problème du trafic entre les zones nord et sud de la ville de Hambourg, a
une longueur totale de $3.325 \mathrm{~m}$. La plus une longueur totale de $3.325 \mathrm{~m}$. La plus
grande partie de son parcours dispose d'un système d'aération spécial, entretenu par systeme
trois stations de ventilation.

Le tunnel est constitué par trois tubes de circulation indépendants, à deux voies chacun. Les tubes latéraux canalisent le trafic à sens unique, tandis que le central per
la circulation dans les deux directions.

Dans le tronçon sous le lit du fleuve, les trois tubes, avec leurs conduits de ventila tion, se groupent dans une piece unique male. Ce troncon se compose de huit élé. ments construits dans une cale sèche du voisinage, pour les enfoncer et les poser postérieurement au fond du fleuve, dans une tranchée préalablement creusée et draguée. Le tronçon est complété par des procédés technologiques très avancés de scellemen de tous les joints anancé la tranchée étant ment.

Le tronçon sous la déclivité la plus pronon cée, qui est une construction en béton armè qui relie les tronçons du tunnel, comme c'est le cas des deux autres stations, dis.
pose, en plus, de la centrale de sécurité pose, en plus, de la centrale de sécurité munie des techniques les plus modernes.

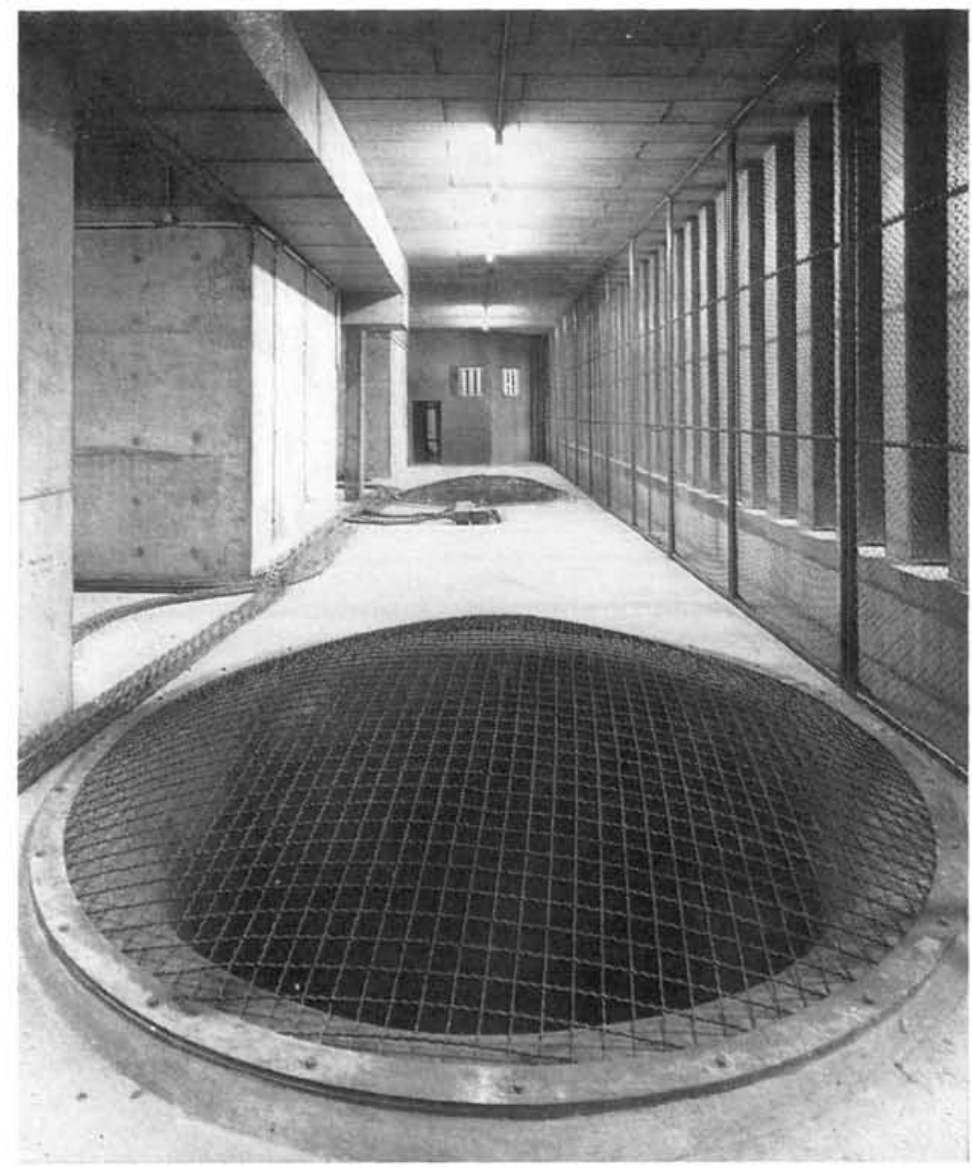

FOTOS: HANS MEYER-VIEDEN

\section{summary}

Tunnel under the river Elbe Hamburg - West Germany

This important work, constructed to solve the traffic problem between the northern and south of $3,325 \mathrm{~m}$. The tunnel is provided with special part of the suplied by three ventilation stations.

The tunnel is made up of three independent circulation tubes, each with two traffic one way traffic, whereas the middle lane is designed for two way traffic.

In the section under the river itself, these three tubes, along with the ventilating ducts, come together into one single rectangula piece. This particular stretch consists of eight members, which were constructed in laid on the river bottom, along a previously excavated trench. It was completed by means of highly advanced technologica methods for sealing the joints and subwas again covered up with the excavation material.

The section under the greatest slope of the river bed was excavated by means of the method of the advancing driller pipe shield, and the end sections were so near the surface that the work was carried out in

The northern ventilation station $-\mathrm{a}$ reinforced concrete construction, connecting sections of the tunnel-further contains the safety and control stations for the entire the most modern technical devices.

\section{zusammenfassung}

Der Elbtunnel - Hamburg . Bundesrepublik Deutschland

Dieser bedeutende Bau, der konstruiert worden ist, um das Verkehrsproblem zwischen dem nordlicen und suadichen Teil zu Der grösste Teil des Tunnels ist mit einer besonderen, von drei Lüftungsstationen be dienten Lüftung ausgerüstet.

Der Tunnel besteht aus drei getrennten, je zwei-spurigen Verkehrsröhren. Die äusseren kehr reserviert während für Verkehr in beiden Richtungen abgesehen ist.

In der Stromstrecke werden die drei 2-spuri gen Verkehrsrohre, einschliesslich der Luftnitt zusammengefügt. Diese Strecke wird aus 8 Tunnelelementen dargestellt, die in einem Baudock vorgefertig, durch Absenkverfahre in einer Rinne im Strombett verlegt und miteinander verbunden wurden. Der Fugen schluss wurde mit den modernsten technolo gischen Methoden ausgeführt ind der zuvo ausgehobene Graben wurde wieder mit dem
ausgebaggerten Material verfüllt. Die Strecke unter dem grössten Gefälle wurde mit dem Vorbaubbrustschildverfahren ausgehoben und die Endstrecken waren de Oberflache so nahe, dass der Bau im Freien
ausgeführt werden konnte.

Die nördliche Luftungsstation -eine Stahlbetonkonstruktion, die Sektoren des Tunnels verbindet- enthält noch die mit den modern Sten technischen Anlagen aus 